\title{
Age-Adjusted Mortality Rate
}

National Cancer Institute

\section{Source}

National Cancer Institute. Age-Adjusted Mortality Rate. NCI Thesaurus. Code C53360.

The death rate, or proportion of a given population that dies, during a specified time period, statistically modified to eliminate the effect of the various age distributions. 